\title{
Environmental Assessment of Industrially Applied Drying Technologies for the Treatment of Spirulina Platensis
}

\author{
Sofia Papadaki ${ }^{1,2}$, Konstantina Kyriakopoulou ${ }^{1}$, Marina Stramarkou ${ }^{1}$, \\ Ioannis Tzovenis ${ }^{2}$, Magdalini Krokida ${ }^{1}$ \\ ${ }^{1}$ School of Chemical Engineering, National Technical University of Athens, Greece \\ ${ }^{2}$ MicroPhykos, Greece
}

\begin{abstract}
Spirulina platensis is a high protein content cyanobacterium with known therapeutic properties. Its main protein Phycocyanin is currently as a functional ingredient into various food products to enhance their nutritional qualities acting as food colorant, antioxidant and emulsifier, reducing the use of synthetic additives. The post-harvest treatment of the microalga affects its content of proteins and pigments (carotenois, chlorophylls, etc.), as in the long run the environmental performance of the recovery process. In this study, industrially applied drying techniques, such as Accelerated Solar Drying (ASD) and Vacuum Drying (VD), were examined. The untreated Spirulina biomass showed the highest content in pigments and antioxidant activity, while in the case of dried biomass a significant decrease of the bioactivity was observed. ASD performed better on phycocyanin recovery, while VD showed higher total carotenoids content. Finally, ASD process showed a higher impact in all environmental impact categories, while VD's cultivation and harvesting stage prior to drying showed significantly higher energy and carbon footprint.
\end{abstract}

Keywords: Accelerated Solar Drying, Antiradical activity, Carotenoids, Life cycle assessment, Phycocyanin, Vacuum Drying

\section{Introduction}

Microalgae are microscopic photosynthetic organisms that are found in marine and freshwater environments and have been exploited for centuries as food and feed [1]. Nowadays, more and more recent achievements that prove the ability of obtaining various high-value molecules such as carotenoids, phycocyanin and chlorophylls, from microalgae have been published. Thus, the microalgal use in diversified sectors, including pharmaceutical, energy and food industries, has become especially attractive, with the latter sector taking more advantage of their technology all over the world [2]. Microalgae not only can enhance the nutritional content of conventional food but also they can positively affect the human health [3]. Spirulina Platenis (SP) is among the most commonly used microalgae in the food sector. SP is a filamentous cyanobacterium that is produced commercially for alimentary use, as a dietary supplement and food additive, or industrial use, as colorant and emulsifier. Currently, the annual production of Spirulina exceeds 3000 tons on a dry weight basis and is realized by many companies in different countries; with China and India being the world leaders [4], [5]. The extensive production of Spirulina is due to its original chemical composition. This bluegreen alga is an excellent natural source of proteins, polyunsaturated fatty acids and vitamins. However, SP has gained increasing attention from research communities due to its high content in the photosynthetic pigments of chlorophyll a, carotenoids and phycocyanin, which present additional antioxidant properties [6]. Significant attention is paid to phycocyanin, which is Spirulina's main pigment and reaches up to $20 \%$ in dry weight of the cell protein. phycocyanin has been already used as a food pigment and colouring and is generally known for its antioxidant, anti-inflammatory, hepatoprotective and free radical properties [6], [7].

The high moisture content of microalgae however, makes the handling of the material extremely difficult; therefore dehydration operations are often used. The main objectives of drying are the extension of the shelf life of foodstuffs by minimizing the microbial growth and the reduction of weight, storage and transportation costs [6]. Dehydration of Spirulina is an essential step, as the moisture content of the biomass after harvesting may exceed $90 \%$. The drying conditions greatly affect the functional properties and the nutritional value of the microalga, as the phycocyanin content may be decreased to $50 \%$ when several methods are used, hence the selection of the drying technique and conditions is of major importance [8]. The most common drying techniques are freeze-drying (lyophilization), spray-drying, vacuum-drying, solar-drying and conventional hot air-drying [9].Vacuum drying is successfully applied to heat-sensitive products, as Spirulina. Vacuum enhances the mass transfer because of the increased pressure gradient between the inside and outside of the sample [10]. The distinctive characteristics of vacuum-drying, including the high drying rate, the low drying temperature and the oxygen deficient environment, favour the preservation of the nutritive value of the dried biomass [11]. However, the cost of the process is high [12]. Solar drying was benefit as using free solar energy can reduce the cost of the operation, playing also an important role for the pathogen reduction [13]. During solar 
drying the degradation of microalgal biomass, through the decomposition of the polysaccharides is very likely, therefore a close control and continuous sampling is needed during the process. This study is a laboratory-scale application with potential scale up practice in drying process of microalgal biomass, since it is the most energy consuming stage in the whole value chain of microalgae production and processing. Drying stage affects directly the total environmental performance including energy and carbon footprint. [14], [15]. The dried methods that studied were: accelerated solar drying and vacuum drying. The dried Spirulina biomass was characterized evaluating spectrophotometrically the pigments content (total carotenoids, chlorophylls, phycocyanin) [16]-[18]. Moreover, the antiradical activity of the dried biomass was evaluated through the DPPH assay. Finally, a comparative life cycle analysis was carried out, using proper databases and software, in order to evaluate the selected drying processes' sustainability.

\subsection{Materials}

\section{Materials and methods}

Spirulina platensis (SP) was delivered after centrifugation in our lab for investigation by MicroPhycos company.The samples were immediately stored at $-30{ }^{\circ} \mathrm{C}$ to avoid any degradation. The moisture content of the material was $88.84 \pm 3.30 \%$ prior to drying.

\subsection{Chemicals}

All solvents and reagents used in the measuring protocols were of analytical grade. Water, methanol, acetone, buffer were purchased from Fisher scientific (UK), while 2,2-diphenyl-picrylhydrazyl (DPPH) reagent was purchased from Sigma-Aldrich (USA).

\subsection{Drying procedure}

Samples of SP were dried using two different drying techniques: Accelerated Solar drying (ASD) and Vacuum drying (VD). In the case of the former, the samples were placed in a laboratory scale accelerated artificial solar dryer, having $1,000 \mathrm{~W} / \mathrm{m}^{2}$ of total light source $(8$ OSRAM-ultravitalux lamps, $300 \mathrm{~W})$ that produce an energy spectrum similar to natural sunlight. In the case of the latter, the samples were placed in an experimental in a vacuum oven (Sanyo Gallenkamp PLC, Leicester, England) maintained at $50 \pm 0.2{ }^{\circ} \mathrm{C}$, until constant weight. The total exposure time in both cases was $3 \mathrm{~h}$. All the experiments were conducted in triplicate and the moisture content was measured after the process. The dried products were stored at $-30{ }^{\circ} \mathrm{C}$ in plastic containers until further treatment.

\subsection{Characterization of bioactive content}

The pigment content, namely total carotenoids and chlorophyll a, was estimated through Jeffrey et al.'s protocol [19], using $90 \%$ acetone as solvent. The phycocyanin content was estimated through Boussiba \& Richmond 's protocol [20] using $100 \mathrm{mM}$ phosphate buffer as solvent. Finally, the antiradical activity was evaluated with the stable radical 2,2-diphenyl-1-picrylhydrazyl (DPPH) [21].

\subsection{Evaluation of the environmental impact}

\subsubsection{Goal and Scope}

The goals of this study was to compare the environmental aspects and impacts associated with different industrially applied drying methods for the production of dried microalgal biomass rich in pigments and especially phycocyanin. Assessing the environmental performance of the proposed technologies and identifying the "hot spots" of the production lines life cycle can lead to the environmental and economic improvement of these processes.

\subsubsection{System investigated}

Commercial microalgae cultivation is generally realised in open raceways which are shallow ponds open or sheltered under a greenhouse. This kind of system is commonly used in the industry to produce microalgae used as foodstuffs [22]. The choice of the growth medium can be done independently from the cultivation system. In this study the cultivation information for 1 ha of algal production over one year was considered as proposed in our previous study [23].It is widely known that one of the major hotspots of microalgae biomass production lies on the concentration step. The moisture content of the wet biomass can exceed $90 \%$ making the handling and conservation of the biomass difficult. Therefore, in order to achieve high concentrations, centrifugation and drying are industrially applied. These dewatering stages were also included in this study. Centrifugation is considered as one of the most energy consuming methods, however with the use of spiral plate [24] or rotary drums [25] reduction on the energy consumption can be achieved. Finally, two industrially applied drying alternatives were considered, solar drying and vacuum drying, which lead to products of different final moisture content $(4 \%$ and $2.5 \%$, respectively). The drying treatment was found experimentally to affect the phycocyanin profile of the microalgae.

\subsubsection{Functional Unit (FU)}

In this study $1 \mathrm{~kg}$ of phycocyanin containing biomass was considered as the FU. This selection was made due to the commercial importance of phycocyanin, which can be used as an additive in food, cosmetic or nutraceutical applications. 


\subsubsection{System boundaries}

The system is modelled for the geographical location of Macedonia, Greece and is based on a fictional microalgae farm. Cradle-to-gate environmental impacts of phycocyanin containing biomass, broken down into two discrete stages, including: the acquisition of the microalgae (cultivation \& harvesting) and the drying treatment to acquire a product of high shelflife still containing this bioactive substances.

\subsubsection{Life cycle inventory}

Life cycle inventory includes input data for the cultivation, harvesting and drying stage of SP biomass. For electricity from the grid, average Greek electricity mix production was estimated as presented from Ecoinvent 2.0 references, while typical raw material extractions and manufacturing processes were inventoried based on readily available data from the Ecoinvent 2.0 database. Mass allocation was performed in all stages and a brief summary of the principal processes and energy and material estimations for the cultivation of the microalgae are shown in Table 1.

Table 1. Resource usage and emissions of the cultivation of microalgae in 1 ha open pond.

\begin{tabular}{|l|l|l|}
\hline Products and Resources & & \\
\hline Microalgae yield & 109500 & $\mathrm{~kg}$ \\
\hline Occupation land open pond & 1 & $\mathrm{ha}$ \\
\hline Occupation land pipelines & 0,04 & $\mathrm{~m} 2 \mathrm{a}$ \\
\hline Occupation land processing & 0,21 & $\mathrm{~m} 2 \mathrm{a}$ \\
\hline Resources & & \\
\hline CO2 & 185 & $\mathrm{t}$ \\
\hline Fertiliser (N) & 896 & $\mathrm{~kg}$ \\
\hline Fertiliser (P) & 615 & $\mathrm{~kg}$ \\
\hline Iron sulphate & 1 & $\mathrm{~kg}$ \\
\hline Water, salt, ocean & 77140 & $\mathrm{t}$ \\
\hline Electricity pumping CO2 & 13.35 & $\mathrm{GJ}$ \\
\hline Electicity paddlewheel & 78.86 & $\mathrm{GJ}$ \\
\hline Electricity pumping water & 60.33 & $\mathrm{GJ}$ \\
\hline Electricity centrifugation & 16.56 & $\mathrm{GJ}$ \\
\hline Traction & 450 & $\mathrm{MJ}$ \\
\hline Emissions to air & & \\
\hline Carbon dioxide & 2.5 & $\mathrm{t}$ \\
\hline Nitrogen & 2.44 & $\mathrm{~kg}$ \\
\hline Emissions to water & & \\
\hline Water & 51500 & $\mathrm{t}$ \\
\hline Salts & 84.7 & $\mathrm{t}$ \\
\hline
\end{tabular}

As far as drying treatment is concerned, significant amounts of energy are needed to evaporate water from the high moisture containing biomass. The evaporation energy for $1 \mathrm{~kg}$ of water is $2.257 \mathrm{~kJ}$, while depending of the drying equipment the efficiency of the process varies. In the case of solar drying the efficiency is considered to be around $50 \%$ since the material is exposed to open air, while for vacuum drying the efficiency can rise up to $80 \%$. Taking into consideration the final moisture content that can be achieved, specifically $4 \%$ and $2.5 \%$ for solar and vacuum drying, respectively, the amount of cultivated and harvested biomass that it is needed to acquire $1 \mathrm{~kg}$ of dried material differs. Taking also into consideration any modification or degradation in the biomass content that occurs during drying, the amount of dried biomass that is equivalent to $1 \mathrm{~kg}$ of phycocyanin can different significantly. Mass and energy balances for the production of $1 \mathrm{~kg}$ of phycocyanin were calculated taking into consideration the experimental results presented in the following section.

\section{Results and discussions}

\subsection{Moisture, pigment content and antiradical activity of Spirulina Platensis biomass}

In Table 2, the moisture and bioactive content of wet and dried biomass are presented. The wet SP biomass exhibited the highest content in pigments and antioxidant activity, while in the case of the dried samples a significant decrease of the bioactivity was observed.

Table 2. Physical characteristics and bioactive content of wet and dried Spirulina Platensis biomass.

\begin{tabular}{|l|l|l|l|l|l|}
\hline & $\begin{array}{l}\text { Moisture } \\
\text { content }(\boldsymbol{\%})\end{array}$ & $\begin{array}{l}\text { Total Carotenoids } \\
(\mathbf{m g} / \mathbf{g} \text { dry base) }\end{array}$ & $\begin{array}{l}\text { Chlorophyll a } \\
\text { (mg/g dry base) }\end{array}$ & $\begin{array}{l}\text { Phycocyanin } \\
(\boldsymbol{\%})\end{array}$ & DPPH (\%) \\
\hline Wet & 88.84 & 197.219 & 320.433 & 4.928 & 30.739 \\
\hline Vacuum & 1.35 & 55.793 & 71.610 & 0.221 & 2.709 \\
\hline Solar & 3.38 & 19.353 & 36.644 & 0.485 & 2.308 \\
\hline
\end{tabular}




\subsection{Environmental impact assessment}

The CML2 baseline 2000 method was chosen among the different LCA impact assessment methods available with Simapro 7.1 software, in order to provide a measure for the potential environmental damage of airborne, liquid and solid emissions by means of appropriate equivalence factors to selected reference compounds for several impact categories, such as Abiotic Depletion Potential (ADP), Global Warming Potential (GWP), Ozone Depletion Potential (ODP), Human Toxicity Potential (HTP), etc. More specifically, the environmental impacts of cultivation, harvesting and drying procedures were evaluated. Drying processing not only creates differences on the moisture content of the products but also in their quality as seen from the experimental results. In the following table are shown the mass and energy inputs that are requested per production line in order to recover a final product of dried biomass rich in phycocyanin expresses as $1 \mathrm{~kg}$ of this bioactive substance (Table 3).

Table 3. Inputs for the production of $1 \mathrm{~kg}$ phycocyanin containing Spirulina Platensis biomass.

\begin{tabular}{|l|l|l|l|}
\hline & Wet & Solar & Vacuum \\
\hline Wet biomass (kg) & 204 & 1472.8 & 3620 \\
\hline Dry biomass (kg) & 20.4 & 206.2 & 452.5 \\
\hline Water evaporated (kg) & - & 1266.6 & 3167.5 \\
\hline Evaporation efficiency & - & $50 \%$ & $80 \%$ \\
\hline Energy for drying (GJ) & - & 10.7 & 8.6 \\
\hline
\end{tabular}

The environmental impact of the production of $1 \mathrm{~kg}$ of SP biomass, including the open pond cultivation, the harvest and the dewatering stage of centrifugation for the production of an algae paste of approximately $90 \%$ moisture content, is presented in Table 4. According to Table 4, the Spirulina cultivation affects mainly the marine ecotoxicity and secondly the global warming and human toxicity.

Table 4. Environmental impact for the production of $1 \mathrm{~kg}$ of Spirulina Platensis biomass.

\begin{tabular}{|l|l|l|}
\hline Impact category & Unit & Microalgae cultivation \\
\hline Abiotic depletion & $\mathrm{kg} \mathrm{Sb} \mathrm{eq}$ & $1.37 \times 10^{-2}$ \\
\hline Acidification & $\mathrm{kg} \mathrm{SO} 2 \mathrm{eq}$ & $1.27 \times 10^{-2}$ \\
\hline Eutrophication & $\mathrm{kg} \mathrm{PO} 4---\mathrm{eq}$ & $4.74 \times 10^{-4}$ \\
\hline Global warming (GWP100) & $\mathrm{kg} \mathrm{CO} 2 \mathrm{eq}$ & $1.99 \times 10^{0}$ \\
\hline Ozone layer depletion (ODP) & $\mathrm{kg} \mathrm{CFC}-11 \mathrm{eq}$ & $2.17 \times 10^{-7}$ \\
\hline Human toxicity & $\mathrm{kg} \mathrm{1,4-DB} \mathrm{eq}$ & $1.53 \times 10^{0}$ \\
\hline Fresh water aquatic ecotox. & $\mathrm{kg} \mathrm{1,4-DB} \mathrm{eq}$ & $1.09 \times 10^{-1}$ \\
\hline Marine aquatic ecotoxicity & $\mathrm{kg} \mathrm{1,4-DB} \mathrm{eq}$ & $2.66 \times 10^{2}$ \\
\hline Terrestrial ecotoxiciWty & $\mathrm{kg} 1,4-\mathrm{DB}$ eq & $9.48 \times 10^{-3}$ \\
\hline Photochemical oxidation & $\mathrm{kg} \mathrm{C} 2 \mathrm{H} 4$ & $6.38 \times 10^{-4}$ \\
\hline
\end{tabular}

Taking into consideration the biomass needed for the production of $1 \mathrm{~kg}$ of phycocyanin, based on different drying techniques (see Table 3), the environmental impact of each feedstock was formed as follows (Table 5).Vacuum dried presented high energy demand for the cultivation of vast quantities of biomass containing phycocyanin. It presented higher environmental impact in the impacts only in the categories of global warming potential, abiotic depletion and Fresh water aquatic ecotoxicity.

Table 5. Environmental impact for the production of $1 \mathrm{~kg}$ phycocyanin equivalent wet and dried Spirulina Platensis biomass.

\begin{tabular}{|l|l|l|l|l|}
\hline Impact category & Unit & Wet & Solar & Vacuum \\
\hline Abiotic depletion & $\mathrm{kg} \mathrm{Sb} \mathrm{eq}$ & $2.79 \times 10^{0}$ & $5.85 \times 10^{1}$ & $8.03 \times 10^{1}$ \\
\hline Acidification & $\mathrm{kg} \mathrm{SO} 2 \mathrm{eq}$ & $2.59 \times 10^{0}$ & $2.41 \times 10^{2}$ & $2.24 \times 10^{2}$ \\
\hline Eutrophication & $\mathrm{kg} \mathrm{PO} 4---\mathrm{eq}$ & $9.67 \times 10^{-2}$ & $2.12 \times 10^{1}$ & $1.81 \times 10^{1}$ \\
\hline Global warming (GWP100) & $\mathrm{kg} \mathrm{CO} 2 \mathrm{eq}$ & $4.06 \times 10^{2}$ & $1.02 \times 10^{4}$ & $1.30 \times 10^{4}$ \\
\hline Ozone layer depletion (ODP) & $\mathrm{kg} \mathrm{CFC}-11 \mathrm{eq}$ & $4.43 \times 10^{-5}$ & $6.36 \times 10^{-1}$ & $5.09 \times 10^{-1}$ \\
\hline Human toxicity & $\mathrm{kg} \mathrm{1,4-DB} \mathrm{eq}$ & $3.12 \times 10^{2}$ & $2.29 \times 10^{3}$ & $5.57 \times 10^{3}$ \\
\hline Fresh water aquatic ecotox. & $\mathrm{kg} \mathrm{1,4-DB} \mathrm{eq}$ & $2.22 \times 10^{1}$ & $3.65 \times 10^{2}$ & $5.58 \times 10^{2}$ \\
\hline Marine aquatic ecotoxicity & $\mathrm{kg} \mathrm{1,4-DB} \mathrm{eq}$ & $5.43 \times 10^{4}$ & $8.49 \times 10^{6}$ & $7.44 \times 10^{6}$ \\
\hline Terrestrial ecotoxicity & $\mathrm{kg} \mathrm{1,4-DB} \mathrm{eq}$ & $1.93 \times 10^{0}$ & $1.61 \times 10^{7}$ & $1.29 \times 10^{7}$ \\
\hline Photochemical oxidation & $\mathrm{kg} \mathrm{C} 2 \mathrm{H} 4$ & $1.30 \times 10^{-1}$ & $3.59 \times 10^{6}$ & $2.87 \times 10^{6}$ \\
\hline
\end{tabular}

Comparing the overall environmental impact of wet, accelerated solar dried and vacuum dried phycocyanin containing biomass, as seen in Fig. 1, the ASD process showed the worst performance in all environmental impact categories, while VD's cultivation and harvesting stage prior to drying showed extremely high energy and carbon footprint. The biomass obtained after VD was poor in phycocyanin demanding higher amount of feedstock in order to obtain the $1 \mathrm{~kg}$ of phycocyanin that had been referred as functional unit during the Life Cycle Assessment. 


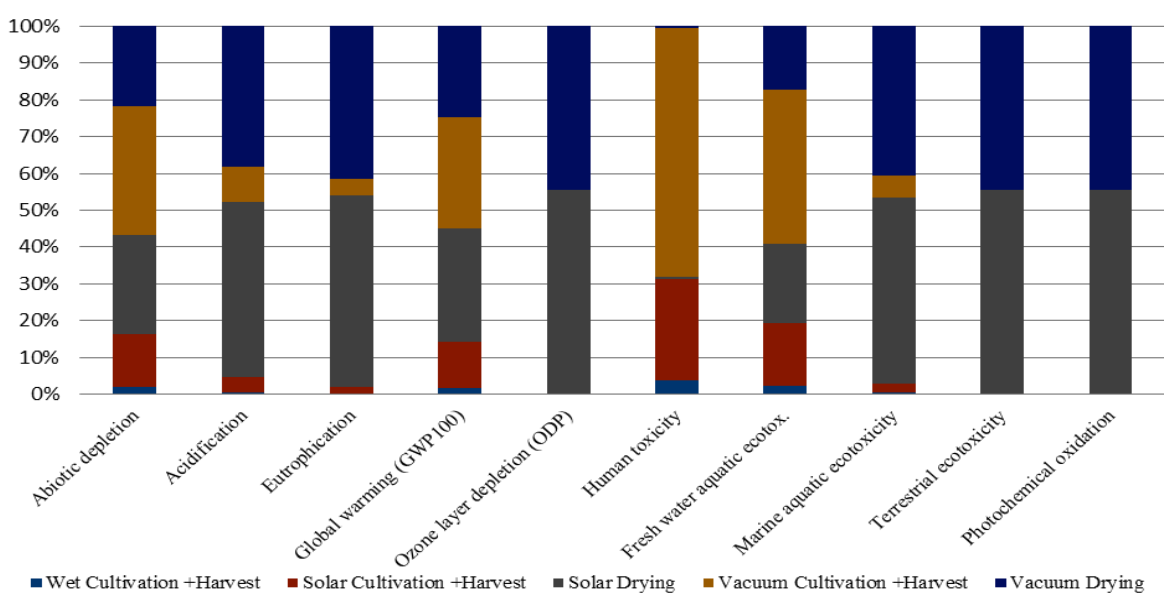

Fig. 1. Impact assessment of the production of $1 \mathrm{~kg}$ phycocyanin containing biomass.

\section{Conclusion}

The drying of microalgal biomass is a crucial procedure that allows the storage, handling and logistics of the raw material. On the other hand, drying is an extremely energy consuming process that affects drastically the final structural and nutritious characteristics of the final product. Specifically, the wet Spirulina biomass showed the highest content in pigments and antioxidant activity, while in dried samples a significant decrease of the bioactivity was observed. ASD performed better on phycocyanin recovery, while VD showed higher total carotenoids content. Furthermore, ASD process showed a higher impact in all environmental impact categories, while VD's cultivation and harvesting stage prior to drying showed extremely high energy and carbon footprint. The biomass obtained after VD was poor in phycocyanin demanding higher amount of feedstock in order to obtain the $1 \mathrm{~kg}$ of phycocyanin that had been referred as functional unit during the Life Cycle Assessment. Finally, taking into consideration that environmental footprint of the microalge production can be allocated to other products as well, such as total carotenoids, chlorophylls, antioxidant compounds and of course the polysacharides of the microalgae itself, the actual impact of phycocyanin production will be significantly lower.

\section{References}

[1]. I. Priyadarshani and B. Rath, "Commercial and industrial applications of micro algae - A review," J. Algal Biomass Util., vol. 3, no. 4, pp. 89-100, 2012.

[2]. M. Vigani et al., "Food and feed products from micro-algae: Market opportunities and challenges for the EU," Trends Food Sci. Technol., vol. 42, no. 1, pp. 81-92, 2015.

[3]. P. Spolaore, C. Joannis-Cassan, E. Duran, and A. Isambert, "Commercial applications of microalgae.," J. Biosci. Bioeng., vol. 101, pp. 87-96, 2006.

[4]. L. C. Wu, J. A. A. Ho, M. C. Shieh, and I. W. Lu, "Antioxidant and antiproliferative activities of spirulina and Chlorella water extracts," J. Agric. Food Chem., vol. 53, no. 10, pp. 4207-4212, 2005.

[5]. H. Shimamatsu, "Mass production of Spirulina, an edible microalga," Hydrobiologia, vol. 512, no. 1-3, pp. 39-44, Jan. 2004.

[6]. E. G. Oliveira, J. H. Duarte, K. Moraes, V. T. Crexi, and L. A. A. Pinto, "Optimisation of Spirulina platensis convective drying: Evaluation of phycocyanin loss and lipid oxidation," in International Journal of Food Science and Technology, vol. 45, no. 8, 2010, pp. $1572-1578$.

[7]. S. T. Silveira, J. F. M. Burkert, J. a V Costa, C. a V Burkert, and S. J. Kalil, "Optimization of phycocyanin extraction from Spirulina platensis using factorial design," Bioresour. Technol., vol. 98, no. 8, pp. 1629-1634, 2007.

[8]. V. Belessiotis and E. Delyannis, "Solar drying," Sol. Energy, vol. 85, no. 8, pp. 1665-1691, 2011.

[9]. E. G. Oliveira, G. S. Rosa, M. A. Moraes, and L. A. A. Pinto, "Phycocyanin content of Spirulina Platensis dried in spouted bed and thin layer," J. Food Process Eng., vol. 31, no. 1, pp. 34-50, 2008.

[10]. M. Stramarkou, S. Papadaki, K. Kyriakopoulou, and M. Krokida, "Recovery of Functional Pigments from four Different Species of Microalgae," IOSR J. Environ. Sci. Toxicol. Food Technol., vol. 10, no. 9, pp. 26-30, 2016.

[11]. L. Wu, T. Orikasa, Y. Ogawa, and A. Tagawa, "Vacuum drying characteristics of eggplants," J. Food Eng., vol. 83, no. 3, pp. 422429, 2007.

[12]. I. Alibas, "Energy Consumption and Colour Characteristics of Nettle Leaves during Microwave, Vacuum and Convective Drying," Biosyst. Eng., vol. 96, no. 4, pp. 495-502, 2007.

[13]. L. Bennamoun, "Solar drying of wastewater sludge: A review," Renewable and Sustainable Energy Reviews, vol. 16, no. 1. pp. 1061-1073, 2012.

[14]. P. C. Tiburcio, F. C. F. Galvez, L. J. Cruz, and V. C. Gavino, "Optimization of low-cost drying methods to minimize lipid peroxidation in Spirulina platensis grown in the Philippines," J. Appl. Phycol., vol. 19, no. 6, pp. 719-726, Aug. 2007.

[15]. A. Prasetyaningrum and M. Djaeni, "Drying Spirulina with Foam Mat Drying at Medium Temperature," vol. 3, no. October, pp. 1$3,2012$.

[16]. S. W. Jeffrey and G. F. Humphrey, "New spectrophotometric equations for determining chlorophylls a, b, c1 and c2 in higher plants, algae and natural phytoplankton. Biochemical Physiology Pflanz 167: 191-194.,” Biochem. Physiol. Pflanz, pp. 191-194, 1975.

[17]. a Ben-Amotz and M. Avron, "On the Factors Which Determine Massive beta-Carotene Accumulation in the Halotolerant Alga Dunaliella bardawil.," Plant Physiol., vol. 72, no. 3, pp. 593-597, 1983. 
[18]. S. Boussiba and A. E. Richmond, "Isolation and characterization of phycocyanins from the blue-green alga Spirulina platensis," Archives of Microbiology, vol. 120. pp. 155-159, 1979.

[19]. S. W. Jeffrey, R. F. C. Mantoura, and S. W. Wright, Phytoplankton pigments in oceanography. 1997.

[20]. S. Boussiba and A. E. Richmond, "C-phycocyanin as a storage protein in the blue-green alga Spirulina platensis," Arch. Microbiol., vol. 125 , no. $1-2$, pp. $143-147,1980$

[21]. C. Drosou, K. Kyriakopoulou, A. Bimpilas, D. Tsimogiannis, and M. Krokida, "A comparative study on different extraction techniques to recover red grape pomace polyphenols from vinification byproducts," Ind. Crops Prod., vol. 75, pp. 141-149, 2015.

[22]. J. A. Del Campo, M. García-González, and M. G. Guerrero, "Outdoor cultivation of microalgae for carotenoid production: Current state and perspectives," Applied Microbiology and Biotechnology, vol. 74, no. 6. pp. 1163-1174, 2007.

[23]. K. Kyriakopoulou, S. Papadaki, and M. Krokida, "Life cycle analysis of $\beta$-carotene extraction techniques,” J. Food Eng., vol. 167, pp. 51-58, 2015

[24]. P. Collet, A. Hélias, L. Lardon, M. Ras, R.-A. Goy, and J.-P. Steyer, "Life-cycle assessment of microalgae culture coupled to biogas production.," Bioresour. Technol., vol. 102, no. 1, pp. 207-14, Jan. 2011.

[25]. L. Lardon, A. Helias, B. Sialve, J.-P. Steyer, and O. Bernard, "Life-Cycle Assessment of Biodiesel Production from Microalgae," Environ. Sci. Technol., vol. 43, pp. 6475-6481, 2009. 